\title{
Radiation Stability of Nafion Membranes used for Isotope Separation by Proton Exchange Membrane Electrolysis
}

E.B. Fox

S.D. Greenway

E.A. Clark

May 2009

Materials Sceince \& Technology

Savannah River National Laboratory

Aiken, SC 29808

This document was prepared in conjunction with work

accomplished under Contract No. DE-AC09-08SR22470 with the

U.S. Department of Energy.

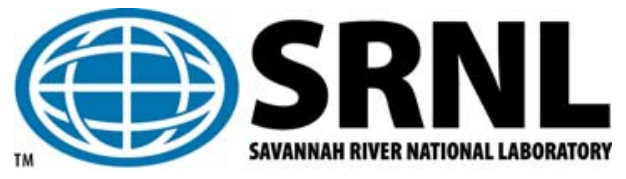


SRNL-STI-2009-00296

Revision 0

\section{DISCLAIMER}

This work was prepared under an agreement with and funded by the U.S. Government. Neither the U.S. Government or its employees, nor any of its contractors, subcontractors or their employees, makes any express or implied: 1 . warranty or assumes any legal liability for the accuracy, completeness, or for the use or results of such use of any information, product, or process disclosed; or 2. representation that such use or results of such use would not infringe privately owned rights; or 3. endorsement or recommendation of any specifically identified commercial product, process, or service. Any views and opinions of authors expressed in this work do not necessarily state or reflect those of the United States Government, or its contractors, or subcontractors.

Printed in the United States of America

Prepared for

U.S. Department of Energy 
Keywords: Nafion 117, radiation degradation, ion exchange capacity, FT-IR, $D M A$, proton exchange membrane electrolysis

Retention: permanent

\section{Radiation Stability of Nafion Membranes used for Isotope Separation by Proton Exchange Membrane Electrolysis}

E.B. Fox

S.D. Greenway

E.A. Clark

May 2009

Materials Sceince \& Technology

Savannah River National Laboratory

Aiken, SC 29808

This document was prepared in conjunction with work accomplished under Contract No. DE-AC09-08SR22470 with the U.S. Department of Energy. 


\section{REVIEWS AND APPROVALS}

\section{AUTHORS:}

E.B. Fox, Materials Science \& Technology

Date

S.D. Greenway, Energy Security

Date

E.A. Clark, Materials Science \& Technology

Date

\section{TECHNICAL REVIEWER:}

T.E. Skidmore, Materials Science \& Technology

Date

\section{APPROVERS:}

T. Adams, Manager, Materials Component \& Welding Technology

Date

R.L. Rabun, III, PDRD Program Manager, DP Engineering

Date

N.C. Iyer, Manager, Materials Science \& Technology

Date 


\section{EXECUTIVE SUMMARY}

Proton Exchange Membrane Electrolyzers have potential interest for use for hydrogen isotope separation from water. In order for PEME to be fully utilized, more information is needed on the stability of Nafion when exposed to radiation. This work examines Nafion 117 under varying exposure conditions, including dose rate, total dosage and atmospheric condition. Analytical tools, such as FT-IR, ion exchange capacity, DMA and TIC-TOC were used to characterize the exposed membranes. Analysis of the water from saturated membranes can provide important data on the stability of the membranes during radiation exposure. It was found that the dose rate of exposure plays an important role in membrane degradation. Potential mechanisms for membrane degradation include peroxide formation by free radicals. 


\section{TABLE OF CONTENTS}

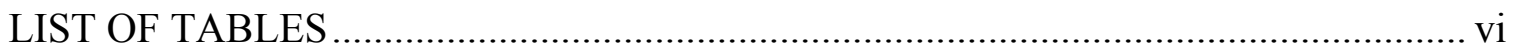

LIST OF FIGURES ...................................................................................... vi

LIST OF ABBREVIATIONS ...................................................................................... vii

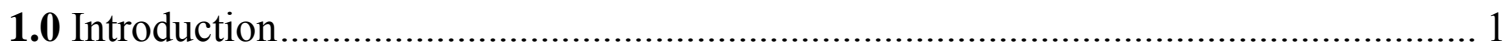

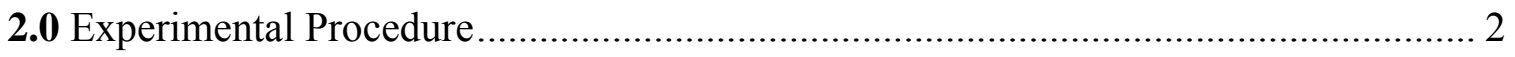

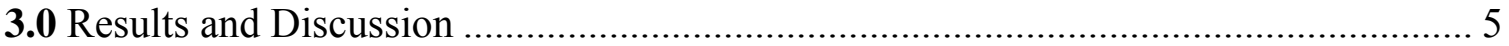

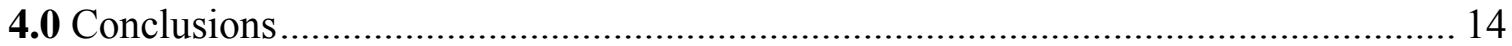

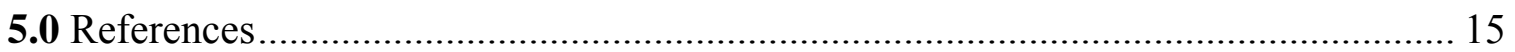

\section{LIST OF TABLES}

Table 1. Gamma irradiation experimental matrix and bend test results................................. 5

Table 2: $\quad$ TIC-TOC and IC Analysis of Water from Water-Soaked, Irradiated Nafion Samples.



\section{LIST OF FIGURES}

Figure 1. Ion exchange capacity results for 1 Mrad gamma irradiated Nafion $117 \ldots \ldots \ldots \ldots \ldots . . . .6$

Figure 2: IEC data from 1-30 Mrad, fast dose, under wet conditions. ........................................ 7



Figure 4: FTIR spectra for Nafion 117 as received, with peak designation................................. 9

Figure 5: FTIR spectra for Nafion 117 irradiated under atmospheric conditions. ........................ 10

Figure 6: Storage Modulus (MPa) as a function of total radiation dosage, when irradiated at 460

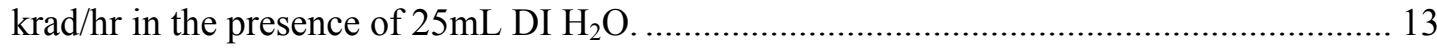

Figure 7. Storage modulus (MPa) as a function of environmental condition and dose rate for as

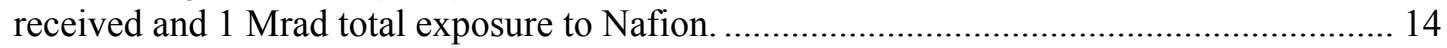


SRNL-STI-2009-00296

Revision 0

\section{LIST OF ABBREVIATIONS}

IR

PEM

TIC-TOC
Infra red

Proton exchange membrane

Total inorganic carbon - total organic carbon 


\subsection{Introduction}

The durability of the polymeric materials during extreme operating conditions is an important consideration when using a Proton Exchange Membranes (PEM) electrolyzer for the separation of hydrogen isotopes. One of the main concerns for the adoption of Polymer Electrolyte Membrane Electrolyzer (PEME) systems for use in tritium isotope separation is the degradation of the Nafion ${ }^{\circledR}$ (DuPont) polymer due to the beta radiation produced by the decay of tritium. Tritium decay gives off beta radiation that has a relatively low average decay energy of $5.69 \mathrm{keV}$.

Testing membranes with tritiated water is difficult because of safety concerns and due to the amount of time needed for membrane exposure. Therefore, gamma irradiation is often used as a substitute for beta irradiation for durability testing and comparisons are made at equivalent radiation dosages. In a previous study, gamma irradiation testing of Nafion ${ }^{\circledR}$ membrane, gasket materials and electrical insulators was completed up to $530 \mathrm{kGy}(53 \mathrm{Mrad})$, the equivalent of 9 $\mathrm{TBq} / \mathrm{kg}$ for two years [1]. It was determined that the strength of the Nafion ${ }^{\circledR}$ membrane and propylene and tetraflouroethylene copolymer gaskets was maintained at doses up to and including 500 kGy (50 Mrad). Two gasket materials, tetraflouroethylene-hexaflouroethylene and perflouroalkoxyethylene copolymers, decreased in strength at 200 (20 Mrad) and $300 \mathrm{kGy}$ (30 Mrad), respectively. During this work it was determined that the main pathway for polymer degradation was direct attack of the polymer by gamma rays. The resulting decomposition was tracked by the quantity of dissolved flouride in the water, as it had a direct correlation to the tensile strength and ion exchange capacity of the Nafion ${ }^{\circledR}$ membrane.

Separately, a small electrolyzer was tested with tritiated water with an activity of 44.4 $\mathrm{GBq} / \mathrm{kg}[2]$. The tensile strength and elongation of the membrane were tested after exposure of both tritiated water and deionized water for six months of operation. It was determined that there 
SRNL-STI-2009-00296

Revision 0

was no appreciable difference between the materials that could be attributed to the beta decay of tritium. The influence of tritium exposure to the separation performance was also negligible.

Previous literature studies have investigated radiation damage to Nafion in PEME systems by performing life tests with tritiated water feed to the system $[2,3]$ and accelerated durability testing using gamma radiation $[1,4]$. In order to determine the viability of PEME electrolyzer systems for tritium isotope separation, additional gamma irradiation studies were designed to extend current understanding and are documented in this paper. Three factors that were tested as part of this work are radiation dosage, irradiation conditions, and radiation dose rate.

\subsection{Experimental Procedure}

\subsection{Gamma Irradiation}

Samples of Nafion 117 (1100 Eq. Wt., $180 \mu \mathrm{m}$ thickness, $100 \mathrm{~cm}^{2}$ ) were irradiated using $\mathrm{a}^{60} \mathrm{Co}$ source. The samples were irradiated either in air or enclosed in a laminate bag with $25 \mathrm{~mL}$ of deionized water. The radiation dose rate of the membrane was controlled to either $460 \mathrm{krad} / \mathrm{hr}$ ("fast") or $1 \mathrm{krad} / \mathrm{hr}$ ("slow"). The final gamma radiation dosage to the membrane materials were controlled to $1,5,10,20,30$ or $100 \mathrm{Mrad}$ (Table 1). It is estimated that a liquid water saturated Nafion membrane would have a maximum annual dosage of 24 Mrad of beta radiation [5]. By this estimate, the radiation dosages correspond to lifetimes of 2 weeks ( $1 \mathrm{Mrad}), 1.25$ years (30 Mrad), and 4 years (100 Mrad). .

\subsection{Bend Test}

After irradiation samples $4 \mathrm{~cm} * 0.5 \mathrm{~cm}$ in size were bent at a $45^{\circ}$ angle. Failed samples broke during the test. The bend test can help indicate enbrittlement of the polymers during radiation exposure. 


\subsection{Ion Exchange Capacity (IEC)}

Ion exchange capacity of the membranes was determined by titration with standardized $\mathrm{NaOH}$. Each sample was weighed and lengths measured prior to treatment. A $0.5 \mathrm{M} \mathrm{H}_{2} \mathrm{SO}_{4}$ solution $(50-60 \mathrm{~mL})$ was used to bathe each membrane for 48 hours to ensure protonation. After the $\mathrm{H}_{2} \mathrm{SO}_{4}$ soaking, each membrane was thoroughly rinsed with deionized water. Samples were then soaked an additional 24 hours in deionized water. Membranes were then transferred to beakers containing $50.0 \mathrm{~mL}$ of $2 \mathrm{M} \mathrm{NaCl}$ ion exchange solution for two hours. The residual salt solutions were titrated with standardized $\mathrm{NaOH}(0.02474 \mathrm{M})$ to the phenolphthalein $(1 \%$ in methanol) end point. KHP primary standard was used to standardize the $\mathrm{NaOH}$ titrant. The samples were rinsed with deionized water and bathed in $0.1 \mathrm{M} \mathrm{HCl}$ for 2 hours. After thorough rinsing with deionized water, membranes were gently blotted dry.

\subsection{Infrared (IR) Spectroscopy}

Infrared spectroscopy studies of the as-received and irradiated membranes were performed using a Nicolet Nexus 670 with a CsI beamsplitter, TGDS detector, and Golden Gate accessory which includes a diamond crystal that allows a single bounce of the infrared beam. Each spectrum was a composite of 128 scans. The resolution of the spectrometer was $4 \mathrm{~cm}^{-1}$. Scans were performed using triangular apodization.

\subsection{Inorganic and Organic Carbon Analysis}

Total Inorganic Carbon (TIC) and Total Organic Carbon (TOC) were determined using an OI Analytical Model 1020A Total Carbon Analyzer. This instrument features a vertical quartz combustion tube packed with supported platinum catalyst, which receives a continuous flow of oxygen at $200 \mathrm{cc} /$ minute. The furnace is normally maintained at $680{ }^{\circ} \mathrm{C}$. Organic-containing samples are introduced into the combustion tube via a fixed volume sampling loop. Through catalytic oxidation, the sample is completely oxidized to $\mathrm{CO}_{2}$ and $\mathrm{H}_{2} \mathrm{O}$. The gas flow sweeps the 
$\mathrm{CO}_{2}$ - containing steam out of the combustion tube, through a condenser, and into a gas/liquid separator to trap most of the $\mathrm{H}_{2} \mathrm{O}$. Final $\mathrm{H}_{2} \mathrm{O}$ removal is accomplished by a Nafion membrane dehumidifier with a countercurrent flow of dry oxygen. The dried $\mathrm{CO}_{2}$ containing gas is then passed through a metallic copper halogen scrubber then to a $\mathrm{CO}_{2}-$ specific Non-Dispersive InfraRed (NDIR) detector for peak quantification. TIC samples are manually injected into the TIC reactor, which contains acidic water solution at room temperature. In this acidic environment, all forms of TIC are purged out of the solution as $\mathrm{CO}_{2}$ by the continuous flow of gas. The gas then continues on through the dehumidifier, where it is dried and then passes through the NDIR detector for measurement. TOC is calculated by a difference: $\mathrm{TC}-\mathrm{TIC}=$ TOC.

\subsection{Ion Chromatography Analysis}

Ion Chromatography (IC) studies were performed for the samples irradiated while enclosed in a laminate bag with DI water. Anion analysis was performed by ion chromatography using a Dionex Ion Chromatography system with an AS3/AG3 separator and guard column set and a carbonate/bicarbonate eluent solution.

\subsection{Dynamic Mechanical Analysis (DMA)}

A TA Instruments model 2980 dynamic mechanical analyzer was used for this study. This device applies a forced vibration on a sample and detects the resulting deflection. The quantities reported here are the storage modulus, loss modulus, and tan $\delta$. The DMA was operated in constant amplitude mode, using the so-called "Force Track" feature. The fiber/film sample holder was used. Samples were cut to $4 \mathrm{~cm} * 0.5 \mathrm{~cm}$ in size. The film is clamped on both ends and tension applied. Preliminary experiments with unexposed samples of each polymer were performed to determine the range of acceptable amplitudes that provide valid DMA data- both large enough to obtain modulus data that did not vary with amplitude, but also within the limit of 
SRNL-STI-2009-00296

Revision 0

linear viscoelasticity. Each DMA experiment involved stabilizing the temperature at $-60^{\circ} \mathrm{C}$ for greater than 10 minutes, then the dynamic mechanical properties were measured while increasing the sample temperature at $1^{\circ} \mathrm{C}$ per minute to $100^{\circ} \mathrm{C}$. Analysis was completed on a minimum of three samples at each condition.

\subsection{Results and Discussion}

Samples were subject to a bend test [6] after irradiation as a test for embrittlement. All samples passed the test, except for the 100 Mrad exposures. All exposed samples appeared yellow after radiation exposure. Discoloration was the same, regardless of dose rate.

Table 1. Gamma irradiation experimental matrix and bend test results.

\begin{tabular}{cccc}
\hline $\begin{array}{c}\text { Radiation } \\
\text { Dosage }\end{array}$ & $\begin{array}{c}\text { Irradiation } \\
\text { Conditions }\end{array}$ & Dose Rate & Bend Test \\
\hline $\mathrm{N} / \mathrm{A}$ & $\mathrm{N} / \mathrm{A}$ & $\mathrm{N} / \mathrm{A}$ & pass \\
$1 \mathrm{Mrad}$ & Wet & $460 \mathrm{krad} / \mathrm{hr}$ & pass \\
$1 \mathrm{Mrad}$ & Wet & $1 \mathrm{krad} / \mathrm{hr}$ & pass \\
$1 \mathrm{Mrad}$ & Atmospheric & $460 \mathrm{krad} / \mathrm{hr}$ & pass \\
$1 \mathrm{Mrad}$ & Atmospheric & $1 \mathrm{krad} / \mathrm{hr}$ & pass \\
$5 \mathrm{Mrad}$ & Wet & $460 \mathrm{krad} / \mathrm{hr}$ & pass \\
$10 \mathrm{Mrad}$ & Wet & $460 \mathrm{krad} / \mathrm{hr}$ & pass \\
$20 \mathrm{Mrad}$ & Wet & $460 \mathrm{krad} / \mathrm{hr}$ & pass \\
$30 \mathrm{Mrad}$ & Wet & $460 \mathrm{krad} / \mathrm{hr}$ & pass \\
$100 \mathrm{Mrad}$ & Atmospheric & $460 \mathrm{krad} / \mathrm{hr}$ & fail \\
\hline
\end{tabular}

Nafion 117 has a nominal equivalent weight of $1100 \mathrm{~g} / \mathrm{mol}$ and the measured Ion Exchange Capacity (IEC) for as-received samples ranges between 0.90 and $1.01 \mathrm{meq} / \mathrm{g}$ according to data sheets from the manufacturer (DuPont) [7]. Figure 1 shows the IEC data for the asreceived and irradiated Nafion samples at 1 Mrad dosage and under different irradiation conditions. The as-received sample has an IEC at the lower end of the range expected by the 
manufacturer. The agreement with manufacturing data supports the general accuracy of testing methodology for IEC studies.

The IEC results for 1 Mrad samples are very similar under both atmospheric (dry) and wet irradiation conditions and with both fast and slow radiation dose rates. However, at 1 MRad the overall radiation dosage is relatively low and it may be difficult to see differences in these results. For radiation doses up to $30 \mathrm{Mrad}$, there is a decrease in the IEC as the radiation dosage increased. This decrease in the IEC probably reflects the loss of $\mathrm{SO}_{3}{ }^{-}$groups due to the irradiation.

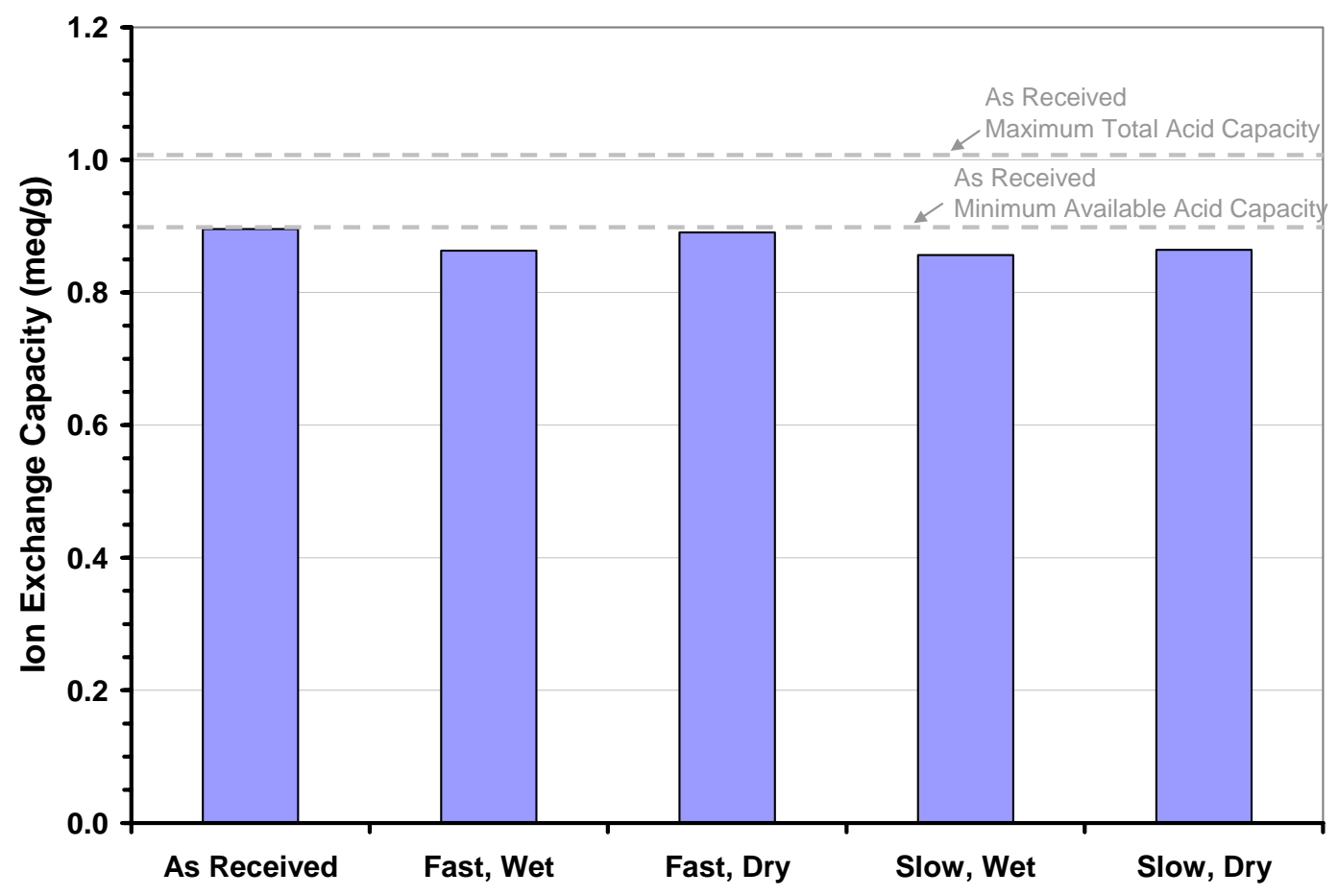

Figure 1. Ion exchange capacity results for 1 Mrad gamma irradiated Nafion 117.

During IEC testing on the 30 Mrad and 100 Mrad atmospheric samples, it was noted that these samples became brittle and fell apart easily. This suggests that the samples may have been irradiated past the point where they would fail in a PEME. The results in Figure 2 show a slight 
general decay of the IEC with radiation dosage. This is similar to the trend from previous literature [1] for effect of gamma irradiation on wet membrane. However, the decay in the IEC for the atmospherically dosed samples shown in Figure 1 is considerably larger than seen in samples dosed in liquid water [1]. Faster degradation of the mechanical properties for atmospherically dosed samples compared to water dosed samples was observed in reference [1], however, the IEC was not tested for the atmospherically dosed membranes in that work. Iwai et al. [4] hypothesized that more rapid degradation of Nafion in an atmospheric environment was due to creation of oxygen radicals and their attack on the membrane backbone. The authors also hypothesized that hydroxide radicals were created in water soaked samples and that the hydroxide radicals did less damage to the polymer structure. This theory is a possible explanation the faster degradation in IEC for the samples irradiated in atmospheric conditions. It is also well known that polymers degrade in air because of the presence of oxygen.

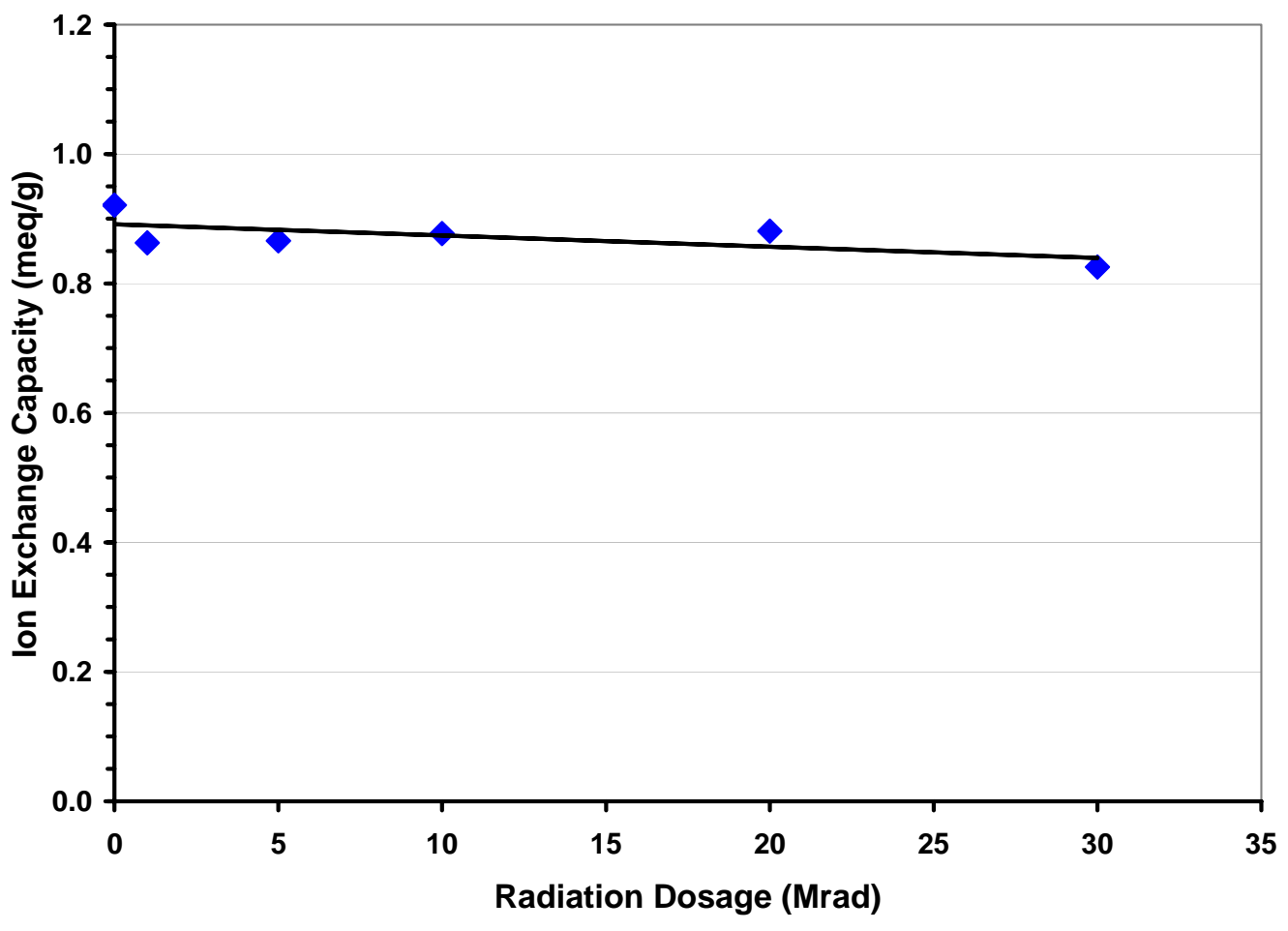

Figure 2: IEC data from 1-30 Mrad, fast dose, under wet conditions. 


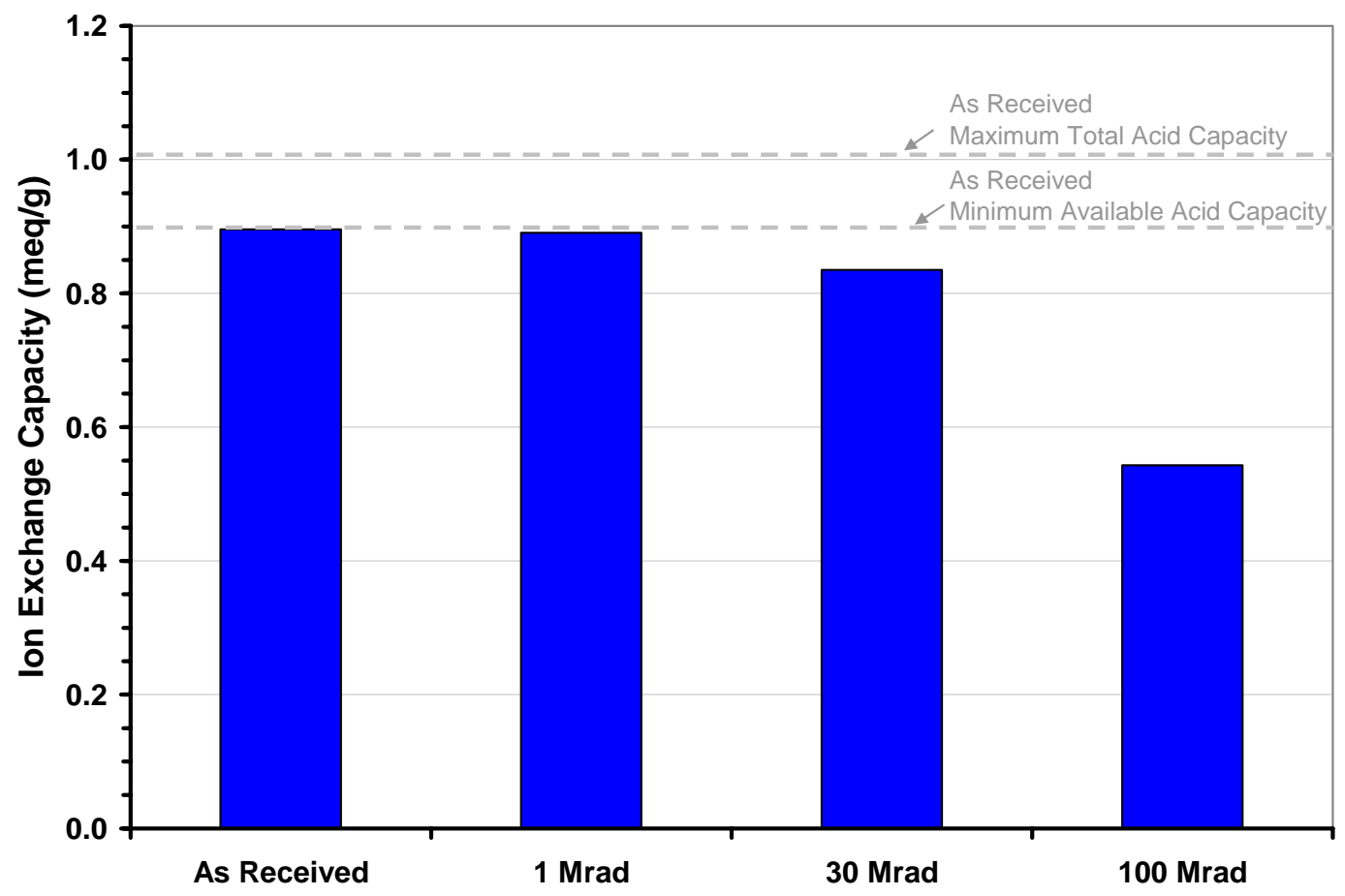

Figure 3: IEC data for atmospheric samples.

Infrared spectroscopy was performed on irradiated membranes to examine the change in bonding in the membrane. A representative spectra of as received Nafion 117 is found in Figure 4. The large peaks at 1100 and $1200 \mathrm{~cm}^{-1}$ representing symmetric and asymmetric stretching of the $\mathrm{CF}_{2}$ bonds show little change with irradiation [8]. The intensity of these peaks changes very little with increasing gamma radiation dosage. The peak at $1760 \mathrm{~cm}^{-1}$ is due to the formation of $\mathrm{CF}=\mathrm{CF}$ bonds in the polymer [9]. Formation of this bond represents defluorination of the polymer. The growth in this peak with radiation dosage indicates the degradation of the polymer. Degradation of this bond should be accompanied by fluoride ion emission from the polymer. Other common peaks that can be identified in this spectrum are: symmetric S-O stretching at $1060 \mathrm{~cm}^{-1}$ with a shoulder at $1310 \mathrm{~cm}^{-1}, \mathrm{C}-\mathrm{F}$ stretching at $980 \mathrm{~cm}^{-1}$, and symmetric C-O-C stretching at $960 \mathrm{~cm}^{-1}[8]$. 


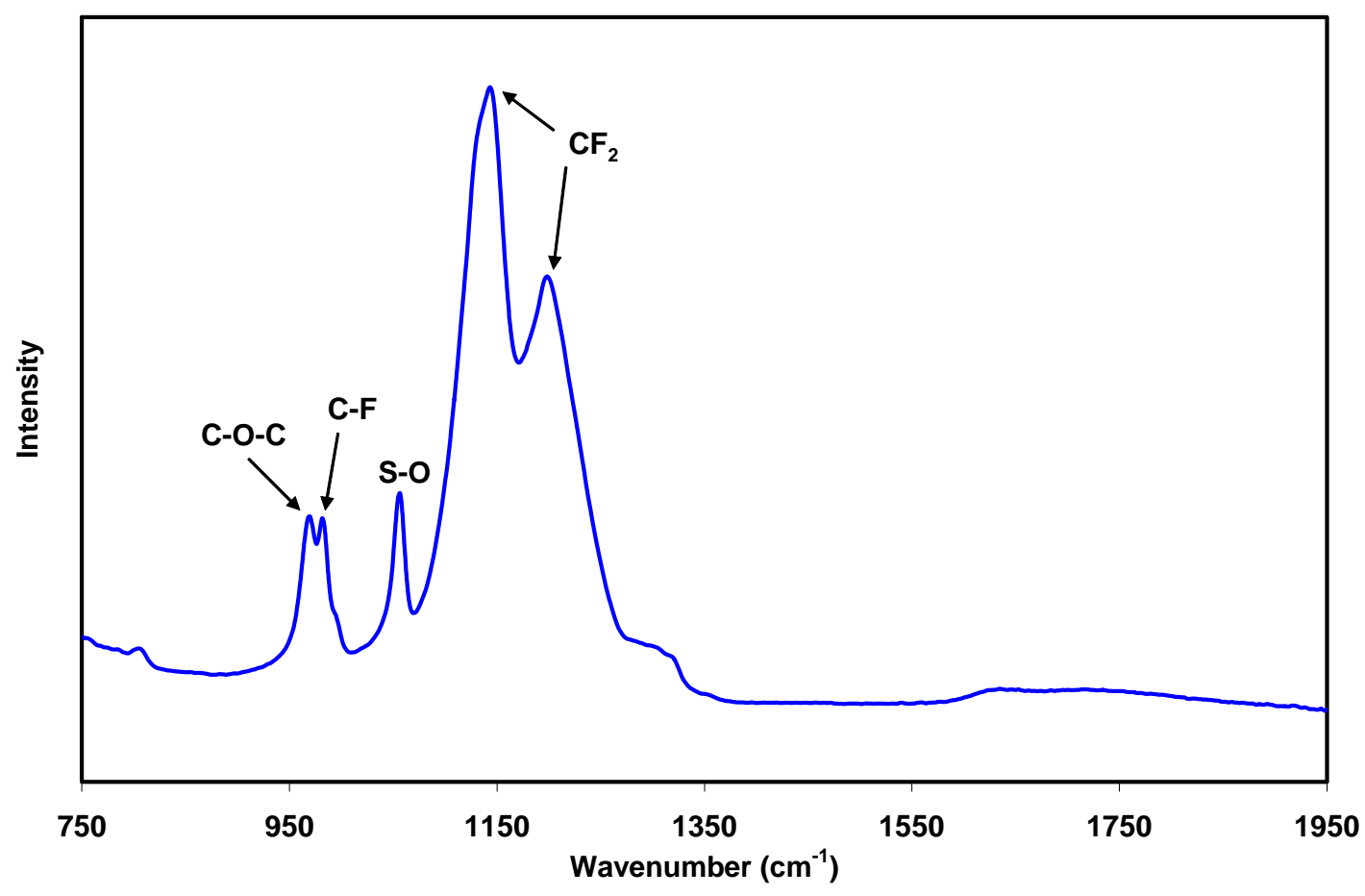

Figure 4: FTIR spectra for Nafion 117 as received, with peak designation.

IR data did not show noticeable differences in the spectra for different irradiation conditions up to $30 \mathrm{Mrad}$, but showed significant differences with atmospheric doses up to 100 Mrad (Figure 5). There also appears to be a decrease in the baseline that may be caused by a change in the infrared refractive index of the sample with radiation exposure. Although the shift in the sample baseline makes analysis more difficult, it appears that there is a decrease in the S-O peak at $1060 \mathrm{~cm}^{-1}$ with increasing radiation dosage. This would correspond to the loss of $\mathrm{SO}_{3}{ }^{-}$ groups in the membrane. Loss of $\mathrm{SO}_{3}{ }^{-}$groups in the membrane can be detected by measuring the sulfate ion concentration by ion chromatography for samples irradiated in water $[10,11]$. The increase in the $\mathrm{C}=\mathrm{O}$ could indicate bond cleavage at the $\mathrm{C}-\mathrm{O}-\mathrm{C}$ sites, which corresponds with the decrease in intensity seen in Figure 5. On possible method for formation is through $\mathrm{CF}_{2}$ chain free radical formation. The free radical then reacts with available oxygen to form peroxide radicals [12]. Peroxide formation is a well known degradation mechanism in Nafion membranes 
$[13,14]$. After exposure at $100 \mathrm{Mrad}$, the formation of the $\mathrm{S}=\mathrm{O}$ or S-O-S [14] peak at approximately $1460 \mathrm{~cm}^{-1}$, could indicate the formation of $\mathrm{SO}_{2}-\mathrm{O}-\mathrm{SO}_{2}$ or $\mathrm{SO}_{2} \mathrm{~F}$ species from peroxide radicals [13].

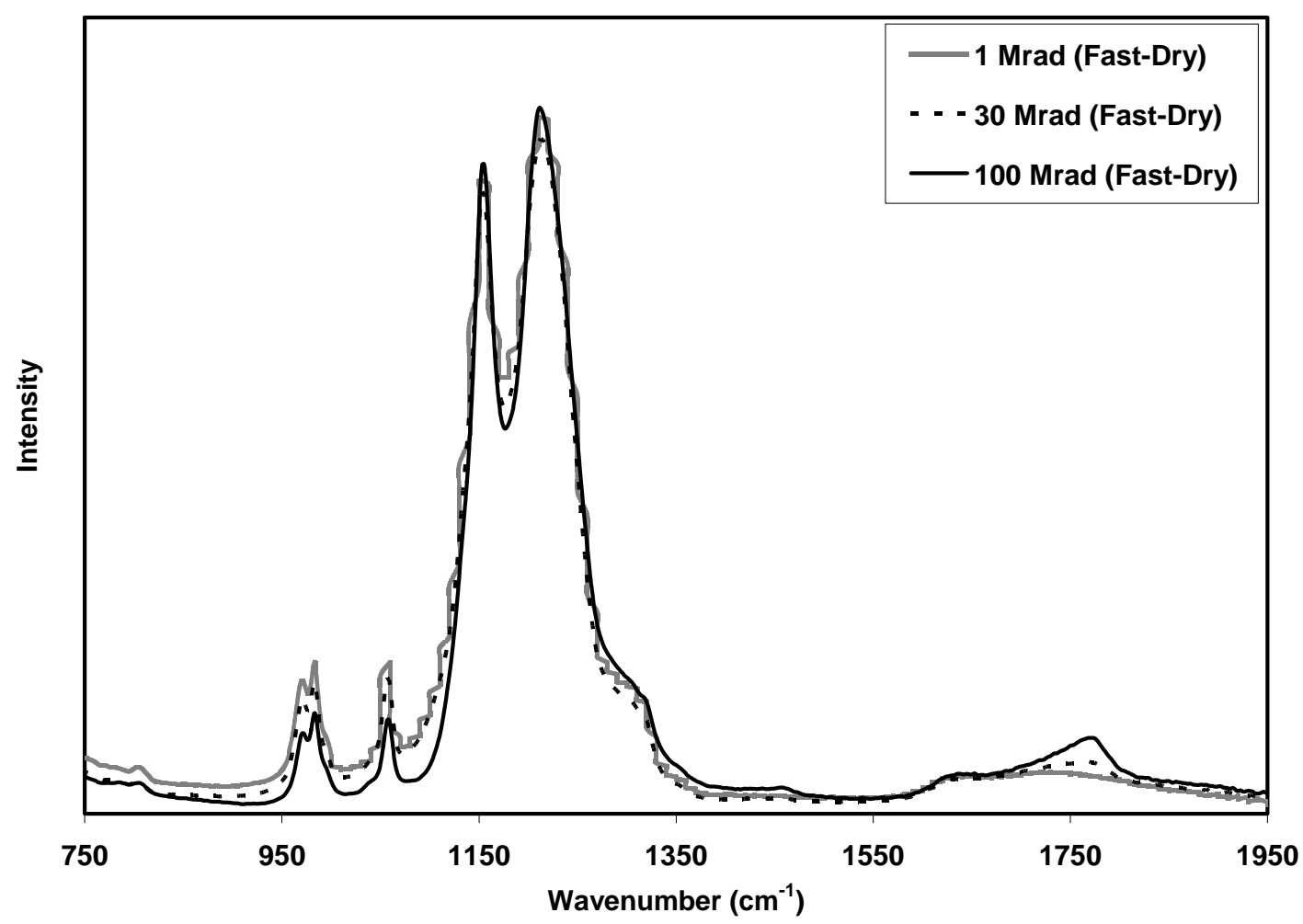

Figure 5: FTIR spectra for Nafion 117 irradiated under atmospheric conditions.

Nafion samples were exposed in water to between 1 to 30 Mrad dose to survey the byproducts of gamma radiation damage to the membrane. Total Inorganic Carbon-Total Organic Carbon (TIC-TOC) and Ion Chromatography (IC) testing were used in product determination. The results from TIC-TOC and IC analysis are presented in Table 2. The analysis below shows the data from a single IC and TIC-TOC analysis of one Nafion sample at each irradiation condition.

TIC-TOC measurements of the amount of carbon dissolved in water were used to quantify the amount of damage to side chains that occurs at locations such as the C-O-C bond. The total amount of organic carbon was relatively small for the as received and 1Mrad fast dosed 
SRNL-STI-2009-00296

Revision 0

samples, however, the organic carbon for the 1 Mrad slow dosed sample was significantly higher.

The TOC for dose rates 5 Mrad and above slowly increased, but were lower than those seen at the 1 Mrad slow dose rate. These preliminary results indicate that radiation dose rate may have a significant effect on the organic carbon content. The inorganic carbon in the water was slightly higher for the irradiated samples and may indicate the presence of longer fluorinated chain fragments that may be generated as a result of gamma irradiation. However, the TIC remained the same for all dose rates. This suggests that initial chain cleavage of the longer fluorinated chains at low dose rates that is independent of total dosage (up to $30 \mathrm{Mrad}$ ).

Table 2: $\quad$ TIC-TOC and IC Analysis of Water from Water-Soaked, Irradiated Nafion Samples. One sigma uncertainty is $10 \%$ for TIC-TOC and $\mathrm{F}^{-}, 15 \%$ for $\mathrm{SO}_{4}{ }^{2-}$.

\begin{tabular}{l|cccc}
\hline $\begin{array}{c}\text { Irradiation } \\
\text { Condition }\end{array}$ & $\begin{array}{c}\text { Total } \\
\text { Organic } \\
\text { Carbon } \\
\left(\mathbf{m g} / \mathbf{g}_{\text {Nafion }}\right)\end{array}$ & $\begin{array}{c}\text { Total } \\
\text { Inorganic } \\
\text { Carbon } \\
\left(\mathbf{m g} / \mathbf{g}_{\text {Nafion }}\right)\end{array}$ & $\begin{array}{c}\mathbf{F}^{-} \\
\left(\mathbf{m g} / \mathbf{g}_{\text {Nafion }}\right)\end{array}$ & $\begin{array}{c}\mathbf{S O}_{4}^{-} \\
\left(\mathbf{m g} / \mathbf{g}_{\text {Nafion }}\right)\end{array}$ \\
\hline As Received & 0.014 & 0.014 & $<0.001$ & 0.01 \\
$\mathbf{1}$ Mrad, Slow & 0.81 & 0.028 & 1.30 & 0.47 \\
$\mathbf{1}$ Mrad, Fast & $<0.007$ & 0.028 & 0.32 & $\mathrm{NR}$ \\
$\mathbf{5}$ Mrad, Fast & 0.16 & 0.028 & 0.16 & 0.10 \\
$\mathbf{1 0}$ Mrad, Fast & 0.24 & 0.028 & 0.36 & 0.14 \\
$\mathbf{2 0}$ Mrad, Fast & 0.38 & 0.028 & 0.77 & 0.27 \\
$\mathbf{3 0}$ Mrad, Fast & 0.55 & 0.028 & 1.23 & 0.42 \\
\hline
\end{tabular}

Fluoride emission from the membrane signals degradation of the Nafion fluoropolymer material $[2,3]$. The fluoride emission from the membrane was determined by IC tests and the results are summarized in Table 2. The 1 Mrad fast dose rate fluoride emission value of 0.32 $\mathrm{mg} / \mathrm{g}_{\text {Nafion }}$ is similar to previous studies [1] performed with similar irradiation rates. The emission values follow a general increasing trend, with the exception of the $5 \mathrm{Mrad}$ sample. Under slow irradiation conditions, the fluoride analysis showed a four times larger fluoride concentration that the Nafion sample irradiated under fast conditions, which is closely approached by the 30 Mrad 
sample. This indicates that the rate of irradiation may have a significant affect the amount of damage to the Nafion. Since differences between the fast and slow irradiation conditions were not observed in either IEC or IR analysis, further testing is needed to better quantify and understand this trend.

The sulfate ion concentration indicates damage to the sulfonic acid groups in the membrane $[2,3]$. The conversion of the sulfonic acid sites in the membrane to sulfate ions is generally attributed to oxygen radical attack on the polymer $[10,11]$. A relationship between the sulfate ion emission rate from the membrane and decrease in the ion exchange capacity may be useful for characterizing membrane degradation in a PEME during operation. If it is assumed that the sulfate ion comes from $\mathrm{SO}_{3}{ }^{-}$groups in the membrane $[2,3]$, then the percentage of damaged sites can be calculated using the equivalent weight of the membrane. Using the IEC measured for the as-received membrane, the sulfate emission of $0.47 \mathrm{mg} / \mathrm{g}_{\text {Nafion }}$ translates to $0.5 \%$ of the total $\mathrm{SO}_{3}{ }^{-}$groups in the as-received membrane. The IEC results show a decrease near $6 \%$ between the as-received membrane and the samples irradiated to 1 Mrad. The difference between these two values indicates that the sulfate ion concentration does not directly correlate to the decrease in the IEC for the membrane. Currently, the reasons for this difference are unknown, but may be due to the generation of products such as $\mathrm{SO}_{2}$ during degradation. The sulfate IC results for 30 Mrad are similar to those of the $1 \mathrm{Mrad}$ slow dose rate, while the sulfate ion concentration decreases from 30-5 Mrad, supporting previous data that the membrane degradation may be highly dependant on dose rate.

Irradiated and as received Nafion samples were analyzed by dynamic mechanical analysis. Samples irradiated at $30 \mathrm{Mrad}$ and above broke during analysis and so could not be analyzed by DMA. These failures indicate severe net degradation of the molecular structure. As can be seen from Figure 6 the storage modulus of the irradiated Nafion membranes rapidly increases up to $5 \mathrm{Mrad}$, then decreases at $-40^{\circ} \mathrm{C}$. The storage modulus reflects the timeindependent elastic constant relating the applied stress to the deflection or strain of the sample. 
SRNL-STI-2009-00296

Revision 0

The increase is interpreted as a net increase of cross-linking in the membrane, and the decrease occurs when the net amount of chain scission and resulting damage of the polymer at the higher doses is greater than the net amount of cross linking [15]. At $60^{\circ} \mathrm{C}$, the storage modulus increases upon initial irradiation to $1 \mathrm{Mrad}$, then decreases to values below the unirradiated samples after this. Although the storage modulus at the two temperatures increased and then decreased, the maxium at $-40{ }^{\circ} \mathrm{C}$ occurred at $5 \mathrm{Mrad}$ dose, while that at $+60{ }^{\circ} \mathrm{C}$ occurred at $1 \mathrm{Mrad}$ dose. The difference in dose to achieve maximum storage modulus reflects the differing reaction to applied stress at the different temperatures. The storage modulus also varies with frequency for most polymers.

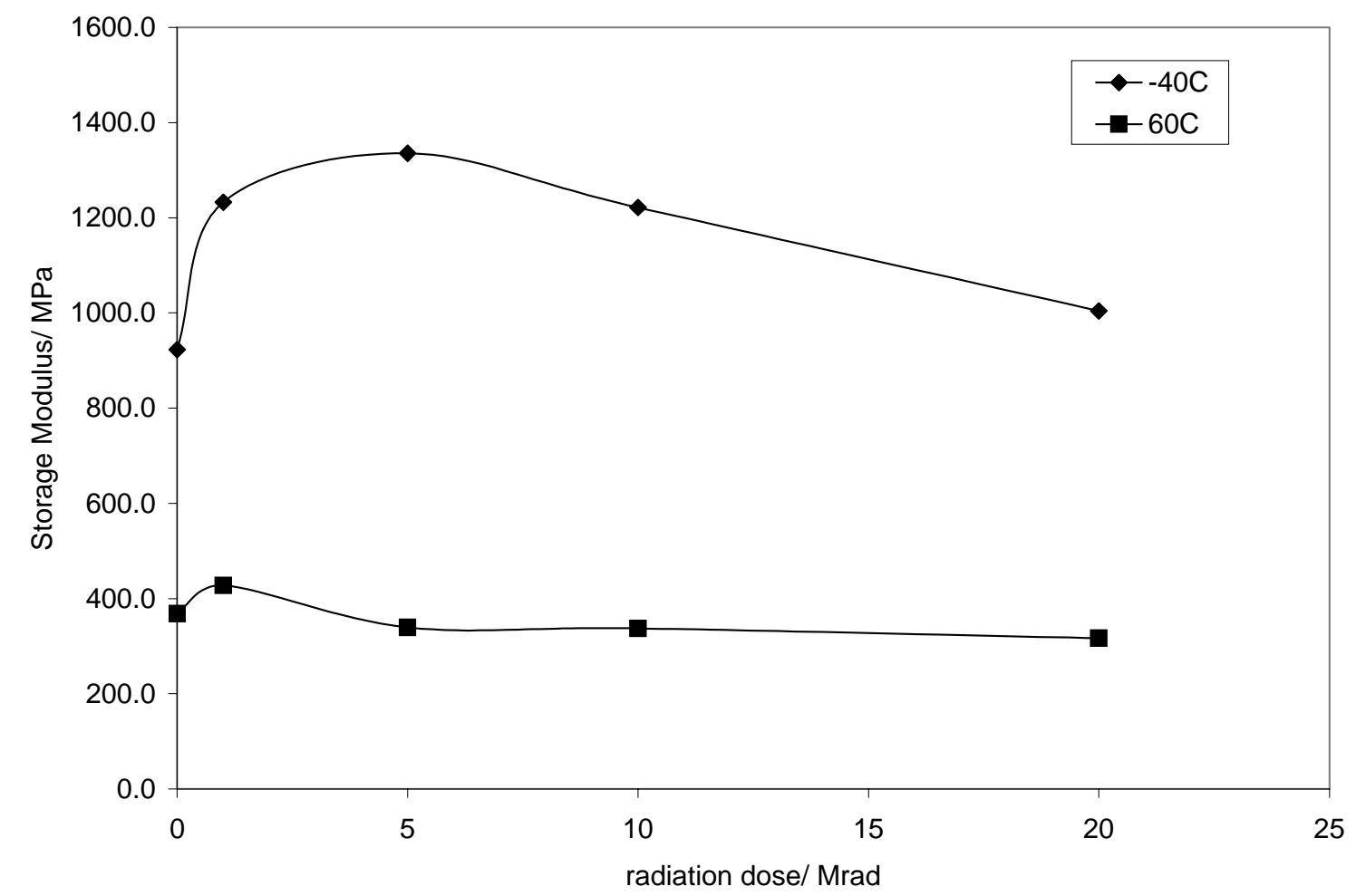

Figure 6: Storage Modulus (MPa) as a function of total radiation dosage, when irradiated at $460 \mathrm{krad} / \mathrm{hr}$ in the presence of $25 \mathrm{~mL} \mathrm{DI} \mathrm{H} \mathrm{H}_{2} \mathrm{O}$.

The storage modulus is compared for samples irradiated to $1 \mathrm{Mrad}$ and unirradiated for various conditions in Figure 7. The unirradiated fully hydrated Nafion samples have a lower 
storage modulus then the as-received samples. The samples that were fully hydrated during irradiation, have higher storage modulus than the dry counterpart, regardless of rate of irradiation. At $60^{\circ} \mathrm{C}$ the storage modulus for all samples represented in Figure 7 falls within $\pm 7 \%$ of the average, which can be considered within experimental error for the system. Larger differences can be seen at $-40^{\circ} \mathrm{C}$. This may be due to the know phase transition in the polymer at $\sim 40^{\circ} \mathrm{C}[16]$.

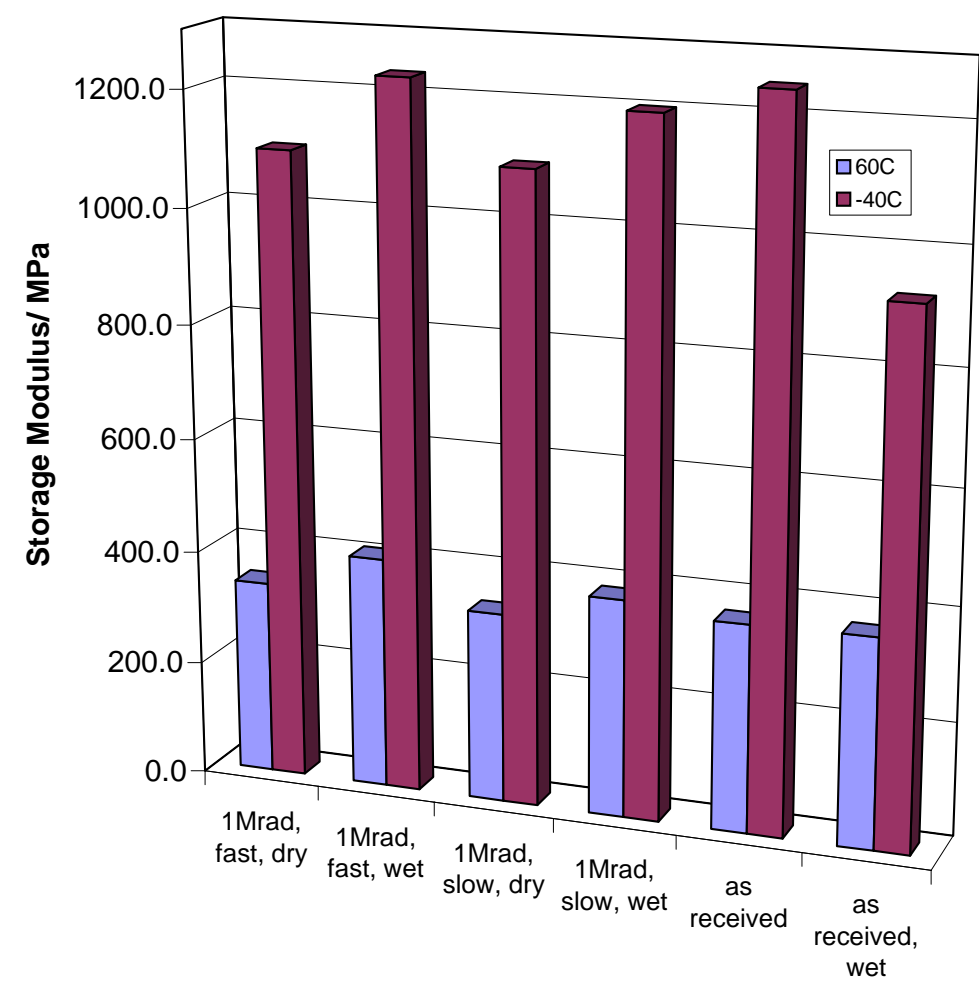

Figure 7. Storage modulus (MPa) as a function of environmental condition and dose rate for as received and 1 Mrad total exposure to Nafion.

\subsection{Conclusions}

Nafion membranes were irradiated with gamma rays from a ${ }^{60} \mathrm{Co}$ source to various doses, dose rates and atmospheric conditions.. The membranes were characterized by IED, IR, fluoride emission, TIC-TOC, and DMA. Samples irradiated to 1 Mrad under wet and atmospheric conditions and at fast and slow irradiation rates had nearly identical IECs and IR spectra. However, the fluoride emission rate for the sample irradiated at a slow rate while soaked in water was significantly higher than the fluoride emission rate for the sample irradiated at a fast rate 
while soaked in water. The $30 \mathrm{Mrad}$ fast dose rate samples corresponded well to the $1 \mathrm{Mrad}$ slow sample. IR data showed increasing formation of $\mathrm{CF}=\mathrm{CF}$ bonds with radiation dosage and also exhibited a decrease in S-O stretching. The changes in these bonds indicate defluorination of the polymer and the loss of acid groups, respectively. TOC analysis of the water soaked increases with total dosage, how ever was found to be dependant on dose rate. A fluoride emission test at 1 Mrad for a high dose rate was similar to previous literature and supported the IR data showing defluorination of the polymer. DMA revealed the expected increase and then decrease of the storage modulus with increasing radiation dose. Sulfate analysis showed that loss of active sites was occurring with increasing dosage. Data suggests that membrane degradation may be highly dependant on the rate of total dose versus the total dose.

\section{Acknowledgment}

Researchers wish to thank Amy Ekechukwu and Bob Rabun, Program Director for NNSA funded SRS PDRD programs. Addition thanks for analytical analysis assistance goes to Kathy White, Fernando Fondeur and Tom White; Gregg Creech for membrane irradiation. This work was supported by SRS PDRD programs. This document was prepared in conjunction with work accomplished under Contract No. DE-AC09-08SR22470 with the U.S. Department of Energy.

\subsection{References}

[1] Iwai Y, Yamanishi T, Nishi M, Yagi T, Tamada M. Durability of irradiated polymers in solid-polymer-electrolyte water electrolyzer. J. Nuc. Sci. Tech. 2005; 42(7): 636-642. [2] Cristescu I, Cristescu IR, Dorr L, Glugla M, Murdoch D, Welte S. Long term performances assessment of a water detritiation system components. Fusion Engr. Design 2006; 81(1-7): 839844.

[3] Michling R, Cristescu I, Dorr L, Fanghanel T, Welte S, Wurster W. Behavior of Solid Polymer Membrane Electrolyzers in Use with Highly Tritiated Water. Fusion Sci. Tech. 2008; 54(2): 470-475. 
[4] Iwai Y, Yamanishi T, Isobe K, Nishi M, Yagi T, Tamada M. Distinctive radiation durability of an ion exchange membrane in the SPE water electrolyzer for the ITER water detritiation system. Fusion Engineering and Design 2006; 81(1-7): 815-820.

[5] Fox EB, Greenway SD, Ekechukwu AA. Hydrogen isotope recovery using a cathode water vapor PEM electrolyzer. Fusion Sci. Tech. 2008; 54(2): 483-486.

[6] Standard test methods for bend testing of material for ductility: Arrangement B for semiguided bend test of thin specimens- one end held. 2004, ASTM E-290.

[7] DuPont. DuPont Nafion PFSA Membranes: N-115, N-117, NE-1110. 2006 [cited 2007];

Available from: http://www.dupont.com/fuelcells/pdf/dfc101.pdf.

[8] Liang ZX, Chen WM, Liu JG, Wang SL, Zhou ZH, Li WZ, Sun GQ, Xin Q. FT-IR study of the microstructure of Nafion((R)) membrane. Journal of Membrane Science 2004; 233(1-2): 39-

44.

[9] Alentiev A, Kostina J, Bondarenko G. Chemical aging of Nafion: FTIR study. Desalination 2006; 200(1-3): 32-33.

[10] Chen C, Levitin G, Hess DW, Fuller TF. XPS investigation of Nafion (R) membrane degradation. Journal of Power Sources 2007; 169(2): 288-295.

[11] Kinumoto T, Inaba M, Nakayama Y, Ogata K, Umebayashi R, Tasaka A, Iriyama Y, Abe T, Ogumi Z. Durability of perfluorinated ionomer membrane against hydrogen peroxide. Journal of Power Sources 2006; 158(2): 1222-1228.

[12] Almeida SH, Kawano Y. Effects of X-ray radiation on Nafion membrane. Poly. Degrad.

Stab. 1998; 62(291-297.

[13] Kinumoto T, Inaba M, Nakayama Y, Ogata K, Umebayahi R, Tasaka A, Iriyama Y, Abe T, Ogumi Z. Durability of perflourinated ionomer membrane against hydrogen peroxide. J. Power Sources 2006; 158(2): 1222-1228.

[14] Qiao J, Saito M, Hayamizu K, Okada T. Degradation of Perflourinated Ionomer Membranes for PEM Fuel Cells during Processing with $\mathrm{H}_{2} \mathrm{O}_{2}$. J. Electrochem. Soc. 2006; 153(6): A967-A974. [15] Phillips DC. Effects of Radiation on Polymers. Materials Science and Technology 1988; 4(85-91.

[16] Rae PJ, Brown EN. The properties of poly(tetrafluoroehtylene) (PTFE) in tension. Polymer $2005 ; 46(8128-8140$. 
SRNL-STI-2009-00296

Revision 0 


\section{Distribution:}

S.D. Greenway, 999-W

E.A. Clark, 773-A

T. Adams, 773-41A

N.J. Iyer, 773-41A

R.L. Rabun III, 235-H

T.E. Skidmore, 730-A 